\title{
Problems in Japan's Aging Society from the Perspective of Lichen Sclerosus
}

\author{
Naohiro Kamoda ${ }^{*}$, Isao Kuroda1, Kenji Shimodaira1, Issei Takizawa1, \\ Masaaki Tachibana2, Teiichiro Aoyagi ${ }^{1}$ \\ ${ }^{1}$ Department of Urology, Ibaraki Medical Center, Tokyo Medical University, Ibaraki, Japan \\ ${ }^{2}$ Department of Urology, Tokyo Medical University Hospital, Tokyo, Japan \\ Email: kamonator@gmail.com
}

Received 27 January 2015; accepted 9 February 2015; published 15 February 2015

Copyright (C) 2015 by authors and Scientific Research Publishing Inc.

This work is licensed under the Creative Commons Attribution International License (CC BY).

http://creativecommons.org/licenses/by/4.0/

(c) (i) Open Access

\begin{abstract}
We encountered 12 elderly patients with lichen sclerosus (LS), a relatively high percentage of whom were living with their families. There is a tendency to assume that elderly people living alone or older facility users with paralysis are more likely to require social care, but we note that elderly people living with their families are also likely to develop LS.
\end{abstract}

\section{Keywords}

\section{Lichen Sclerosus, Aging Society}

\section{Introduction}

Lichen sclerosus (LS), first proposed by Stuhmer et al. in 1928 [1], is a chronic inflammatory dermatosis which usually affects the skin of the anogenital region in women, and the glans penis and foreskin in men (balanitis xerotica obliterans) (Figure 1). It occurs less commonly in extragenital areas. It does not cause any systemic disease outside the skin.

In this study, we report the social problems we become aware of through treating LS patients.

\section{Case Presentation}

Table 1 shows the characteristics of 12 LS patients, whom we treated between June 2006 and November 2013. Their ages ranged from 65 to 82 years (median: 74 years), and their symptoms included pain while voiding, difficulty voiding, frequent urination, and urinary retention. Four patients had diabetes, and all patients had undergone circumcision.

\footnotetext{
${ }^{*}$ Corresponding author.
}

How to cite this paper: Kamoda, N., Kuroda, I., Shimodaira, K., Takizawa, I., Tachibana, M. and Aoyagi, T. (2015) Problems in Japan's Aging Society from the Perspective of Lichen Sclerosus. Case Reports in Clinical Medicine, 4, 69-71. 
Table 1. Patients’ characteristics.

\begin{tabular}{cccccc}
\hline & Age & Chief complaint & DM & Diaper use & Housing \\
\hline 1 & 82 & Difficulty voiding & & & 2 \\
2 & 76 & Difficulty voiding & + & & 1 \\
3 & 74 & Difficulty voiding & & + & 1 \\
4 & 79 & Pollakiuria & + & + & 1 \\
5 & 75 & Incontinence & + & & 2 \\
6 & 80 & Retention & & + & 1 \\
7 & 65 & Difficulty voiding & & + & 2 \\
8 & 75 & Pollakiuria & & + & 2 \\
9 & 80 & Retention & + & & 1 \\
10 & 68 & Difficulty voiding & & & 2 \\
11 & 68 & Difficulty voiding & & & \\
12 & 73 & Difficulty voiding & & + & \\
\hline
\end{tabular}

Housing: 1: living with aged wife, 2: living with family, 3: older facility user.

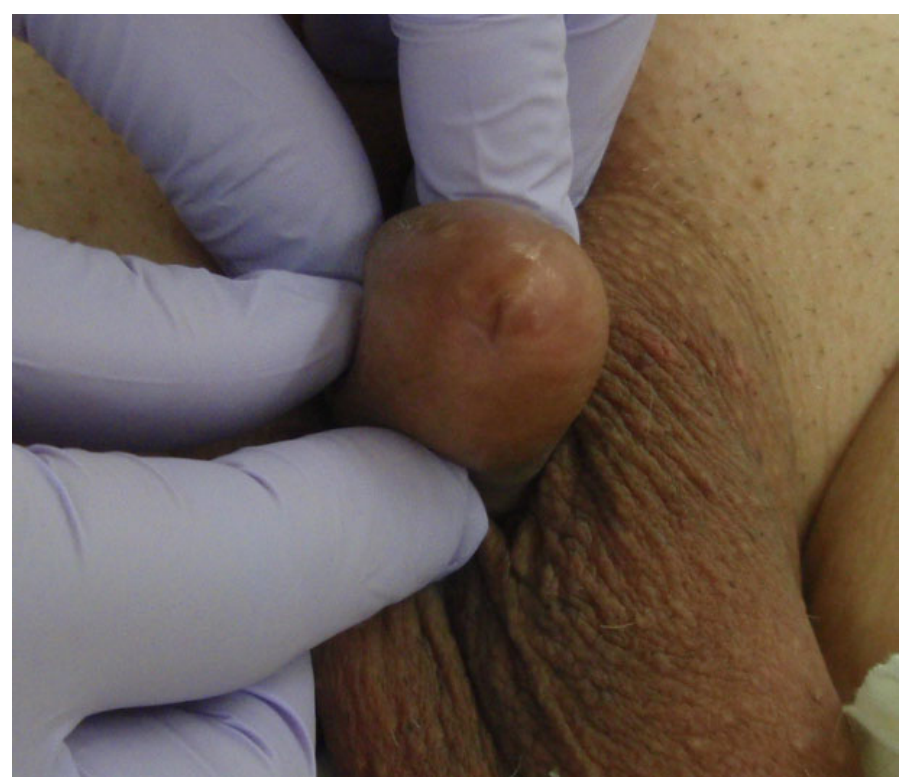

Figure 1. The preputial tissues are fused, resulting in a buried penis.

\section{Discussion}

The risk factors for LS include old age and diabetes, which are likely to result in infection or chronic inflammation. Patients with LS commonly present with urinary disturbance, and so examination of the genital area generally leads to the early detection of LS.

As of October 1, 2012, the total Japanese population was about 127.52 million; of these, people aged <65, 65 - 74, and $\geq 75$ years numbered about 30.79 (24.1\%), 15.60 (12.2\%), and 15.19 (11.9\%) million, respectively. In contrast, as of 1990, the total population was about 123.61 million; of these, people aged $<65$, $65-74$, and $\geq 75$ years numbered about 14.89 (12.0\%), 8.92 (7.2\%), and 5.97 (4.8\%) million, respectively, suggesting that the Japanese population is rapidly aging [2].

Our university hospital, a typical suburban medical center, is situated approximately $50 \mathrm{~km}$ north of Tokyo, 
and is equipped with 389 beds. The population of our medical service area is about 2.84324 million; of these, people aged <65, $65-74$, and $\geq 75$ years number about $6.0661(21.3 \%), 3.4071(11.9 \%)$, and $2.6590(9.4 \%)$ million, respectively, suggesting that this population is a slightly younger demographic than other populations in Japan.

Clinicians perform their duties in consideration of the above-mentioned social backgrounds; however, we sometimes note factors that are overlooked in society.

It is generally considered that LS is more likely to occur among elderly people living alone or those requiring nursing care and diapers, but we identified a higher incidence rate of LS among those living with their families. This suggests that, while the hygiene of the body, including the genital area, is maintained by care workers for elderly people living alone and older care facility users, those living with their families, who are usually considered able to take care of their own personal concerns, insufficiently maintain bodily hygiene, and so are likely to develop LS due to chronic infection of the genital area.

Through some issues regarding the aging of society, we have realized that, as the Japanese population is rapidly aging, it is necessary to alter our perceptions regarding the elderly, such as how they work and participate in society, how community and other environmental factors ought to be for them, and how to prepare for the senile period, in order to better meet the needs of a super-aging society in which all generations will be able to lead a fulfilling life [3]. One of the approaches to achieve this goal is to promote mutual support among the general public, the prevention of elderly people's isolation, and the development of comprehensive community care systems [4]. These opinions were generated mainly because of socially disadvantaged individuals, such as elderly people living alone and demented older adults. However, through our experiences with LS patients, we noted that socially disadvantaged individuals requiring care also include those living with their families who are deemed independent or are considered to require only limited social care.

\section{Conclusion}

There is a tendency to assume that elderly people living alone or older facility users with paralysis are more likely to require social care. However, the incidence of LS is higher among our elderly patients living with their families, based on which we realize that such individuals may also pose a problem in an aging society. Thus, our experiences with LS patients may indicate inadequacies in countermeasures for an aging society.

\section{References}

[1] Stühmer, A. (1928) Balanitis xerotica obliterans (post operationem) und ihre Beziehung zur Kraurosis glandis et praeputii penis. Archiv für Dermatologie und Syphilis, 156, 613-623. http://dx.doi.org/10.1007/BF01828558

[2] Statistics Bureau (2012) Ministry of Internal Affairs and Communications. Population of Census in Japan.

[3] Seike, A. (2011) Panel on Basic Strategy for Aging Society.

[4] Office for Policies on Cohesive Society, Cabinet Office, Government of Japan (2012) White Paper in Aging Society. 
Scientific Research Publishing (SCIRP) is one of the largest Open Access journal publishers. It is currently publishing more than 200 open access, online, peer-reviewed journals covering a wide range of academic disciplines. SCIRP serves the worldwide academic communities and contributes to the progress and application of science with its publication.

Other selected journals from SCIRP are listed as below. Submit your manuscript to us via either submit@scirp.org or Online Submission Portal.
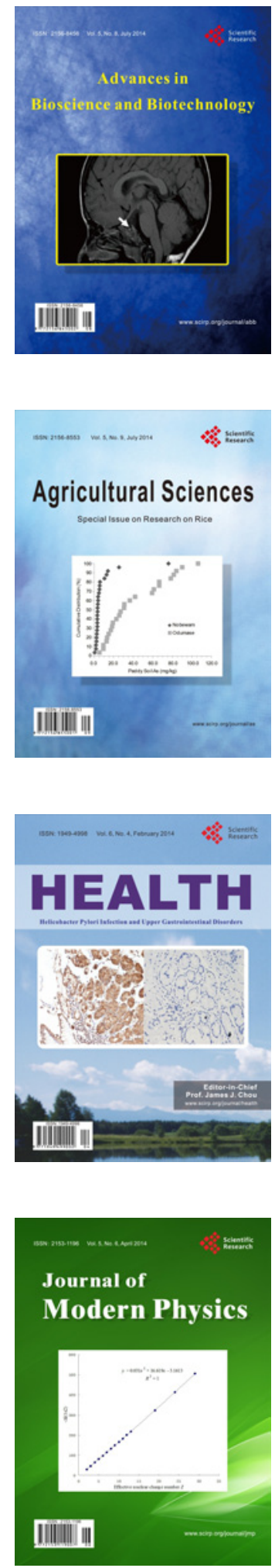
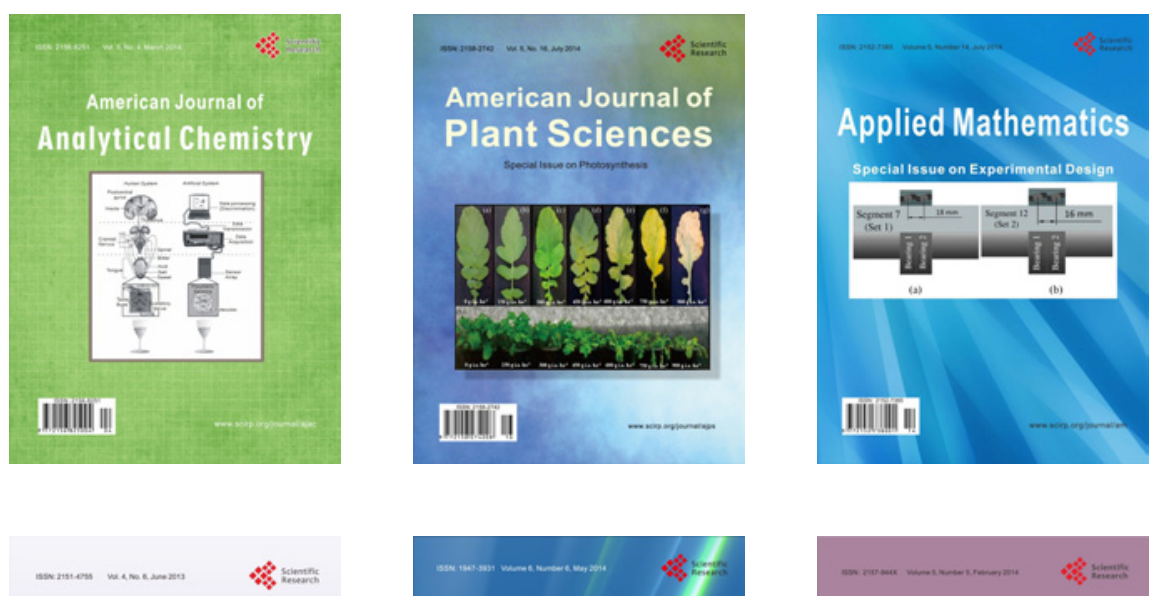

Creative Education
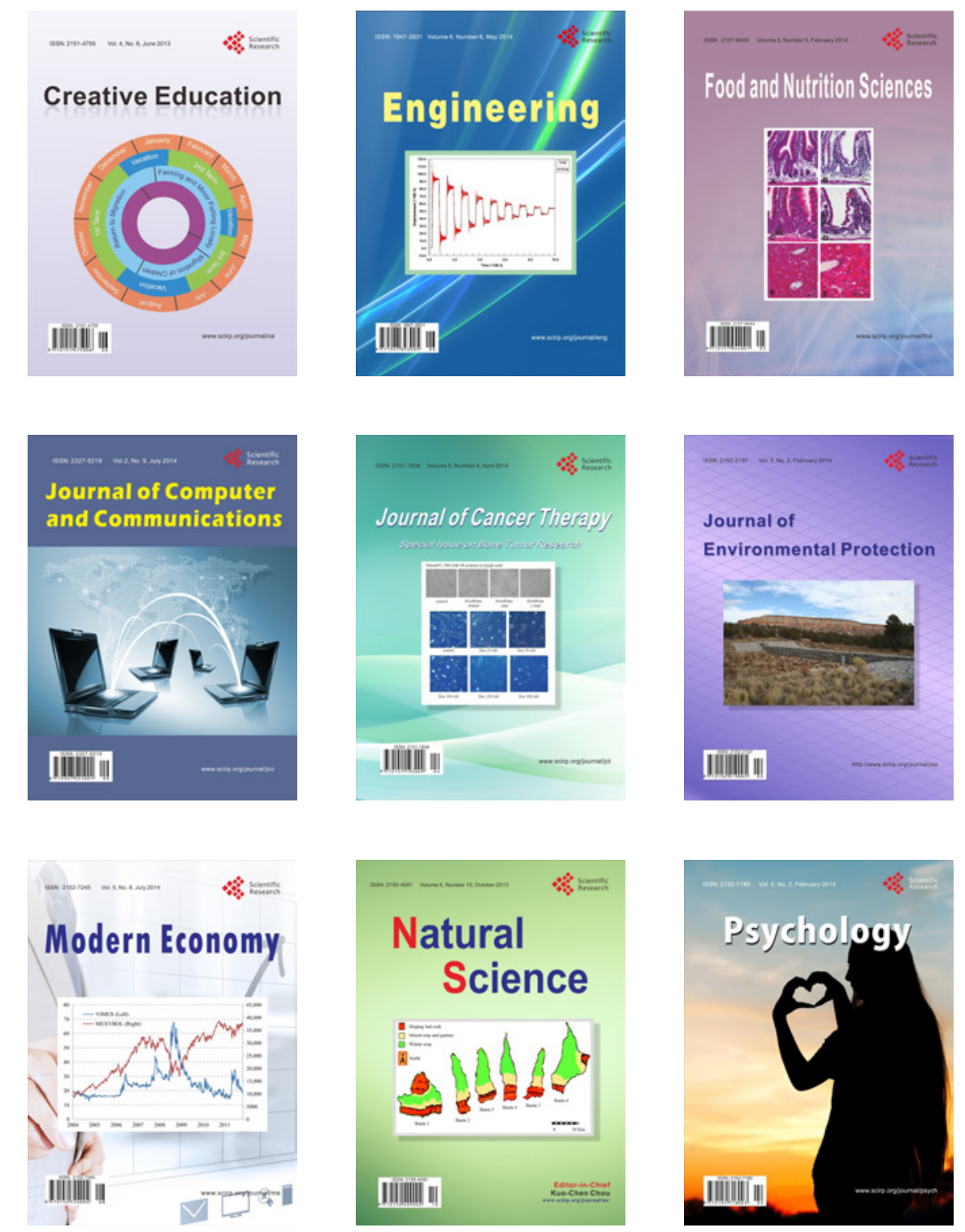